\title{
Therapeutic effects of angiotensin II type 1 receptor blocker, irbesartan, on non-alcoholic steatohepatitis using FLS-ob/ob male mice
}

\author{
JUN KATO, MASAHIKO KODA, MANABU KISHINA, SHIHO TOKUNAGA, TOMOMITSU MATONO, \\ TAKAAKI SUGIHARA, MASARU UEKI and YOSHIKAZU MURAWAKI
}

Division of Medicine and Clinical Science, Department of Multidisciplinary Internal Medicine, Faculty of Medicine, Tottori University, Yonago 683-8504, Japan

Received January 6, 2012; Accepted February 13, 2012

DOI: $10.3892 / \mathrm{ijmm} .2012 .958$

\begin{abstract}
Non-alcoholic steatohepatitis (NASH) is the hepatic manifestation of a metabolic syndrome characterized by accumulation of hepatic fat, inflammation and varying degrees of fibrosis. Angiotensin (AT)-II has been reported to play a role in the establishment of NASH. This study examined the effects of an AT-II receptor blocker, irbesartan, on NASH using fatty liver Shionogi (FLS)-ob/ob male mice as the closest animal model of human metabolic syndrome-related NASH. Irbesartan (30 mg/kg/day) was orally administered to FLS-ob/ob mice for 12 weeks (irbesartan group). The effects of irbesartan on steatohepatitis were examined using factors including steatosis, fibrosis, inflammation and oxidative stress. The areas of hepatic fibrosis and hepatic hydroxyproline content were significantly lower in the irbesartan group compared to controls. The areas of $\alpha$-smooth muscle actin-positivity and F4/80-positive cells were significantly decreased in the irbesartan group. The

Correspondence to: Dr Masahiko Koda, Division of Medicine and Clinical Science, Department of Multidisciplinary Internal Medicine, Faculty of Medicine, Tottori University, 36-1 Nishicho, Yonago, Tottori 683-8504, Japan

E-mail:masakoda@med.tottori-u.ac.jp
\end{abstract}

Abbreviations: ARB, angiotensin II type 1 receptor blocker; FLS, fatty liver Shionogi; NASH, non-alcoholic steatohepatitis; Hyp, hydroxyproline; $\alpha$-SMA: $\alpha$-smooth muscle actin; PCR, polymerase chain reaction; TIMP-1, tissue inhibitor of metalloproteinases-1; TNF- $\alpha$, tumor necrosis factor- $\alpha$; TGF- $\beta 1$, transforming growth factor$\beta 1$; CTGF, connective tissue growth factor; SREBP1c, sterol regulatory element-binding protein 1c; PPAR- $\alpha$, peroxisome proliferator activated receptor- $\alpha$; FAS, fatty acid synthase; 8-OHdG, 8-hydroxy2-deoxyguanosine; ELISA, enzyme-linked immunosorbent assay; 4-HNE, 4-hydroxynoneal; NAFLD, non-alcoholic fatty liver disease; HSCs, hepatic stellate cells; ROS, reactive oxygen species

Key words: non-alcoholic steatohepatitis, angiotensin II type 1 receptor blocker, irbesartan, oxidative stress, liver steatosis, liver fibrosis, fatty liver Shionogi-ob/ob mice percentage of 8-hydroxy-2-deoxyguanosine (8-OHdG)-positive cells and 8-OHdG DNA content were significantly decreased in the irbesartan group compared to controls. Levels of RNA expression for procollagen I, transforming growth factor $\beta 1$, tumor necrosis factor- $\alpha$, sterol regulatory element-binding protein 1c and fatty acid synthase were significantly lower in the irbesartan group compared to controls. In contrast, the gene expression of peroxisome proliferator activated receptor- $\alpha$ was significantly higher in the irbesartan group compared to controls. Irbesartan administration improved hepatic steatosis and attenuated the progression of hepatic fibrosis by inhibiting the activation of hepatic stellate cells and Kupffer cells and reducing oxidative stress.

\section{Introduction}

Non-alcoholic steatohepatitis (NASH) is an advanced stage non-alcoholic fatty liver disease characterized by accumulation of hepatic fat, inflammation and varying degrees of fibrosis. NASH is the hepatic manifestation of a metabolic syndrome and is attracting attention as a major public health problem $(1,2)$. The underlying metabolic abnormalities are related to the progression of liver injury, such as steatosis, necro-inflammation and fibrosis (3).

The renin-angiotensin system (RAS) appears likely to play important roles in various aspects of the metabolic syndrome. For example, the activated RAS increases insulin resistance and oxidative stress (4). The RAS also influences fatty acid metabolism in the liver via activation of angiotensin (AT)-II type 1 receptor (ATR1) or AT type 2 receptor (ATR2) (5). Indeed, AT-II infusion stimulates hepatic triglyceride production and reduces insulin sensitivity (6). A local RAS has been recognized as acting in liver tissue and is reportedly upregulated by several experimental liver injuries $(7,8)$. Blockade of the RAS attenuates hepatic inflammation and fibrosis by suppressing the activation of hepatic stellate cells (HSCs) and oxidative stress (8-10).

Several investigations have demonstrated that AT-II receptor blockers (ARBs) improve insulin resistance, hepatic steatosis and inflammation in NASH models (11-13). However, antifibrotic effects of ARB have yet to be sufficiently elucidated. Although many animal models have been proposed, 
few show all the characteristics of human NASH (14). Most animal models manifest insulin resistance and steatosis, but develop no or only minimal fibrosis. This is problematic, as hepatic fibrosis represents the most important factor in human NASH. We used fatty liver Shionogi (FLS)-ob/ob mice as the model most closely resembling NASH in humans. This mouse model is developed by transferring the $\mathrm{Lep}^{\mathrm{ob}}$ gene into the genome of FLS mice, which then spontaneously develop chronic hepatic steatosis without obesity (15). FLS-ob/ob mice show hyperphagia, obesity, hyperlipidemia and diabetes mellitus and have histologically severe steatosis, hepatocellular ballooning and hepatic advanced fibrosis, and develop cirrhosis and liver tumors (16). FLS-ob/ob mice can thus be considered the animal model closest to the human metabolic syndrome-related NASH. The present study was designed to investigate the antifibrotic effects of irbesartan on NASH in FLS-ob/ob male mice.

\section{Materials and methods}

Animals. Male FLS-ob/ob mice were obtained from Shionogi Research Laboratories (Shionogi, Shiga, Japan). Animals were housed in a room maintained at a controlled temperature of $24 \pm 2^{\circ} \mathrm{C}$ under a 12 -h light-dark cycle. Animals were provided ad libitum access to water and powdery chow made by crushing standard pellet chow. All experiments were carried out in accordance with the Animal Experimentation Guidelines of Tottori University.

Administration of irbesartan. Sixteen male FLS-ob/ob mice (12-weeks-old; mean body weight, $45.7 \mathrm{~g}$ ) were divided into two groups: a control group and an irbesartan group. Mice in the irbesartan group were provided powdery chow containing irbesartan at a dose of $30 \mathrm{mg} / \mathrm{kg} / \mathrm{day}$ for 12 weeks. The concentration of irbesartan mixed with powdery chow was calculated by measuring the food consumption, which was monitored daily.

After 12 weeks, the animals were sacrificed under pentobarbital anesthesia and blood was collected from the right ventricle. Plasma samples were frozen and stored at $-80^{\circ} \mathrm{C}$. The liver and visceral fat were also collected, weighed, snap frozen in liquid nitrogen and stored at $-80^{\circ} \mathrm{C}$. Liver specimens were also fixed in $10 \%$ buffered formalin and embedded in paraffin for histological analysis.

Measurement of blood biochemistry. Aspartate aminotransferase (AST), alanine aminotransferase (ALT), triglyceride and total cholesterol were measured using an autoanalyzer (Hitachi 7170; Hitachi, Tokyo, Japan).

Measurement of liver triglyceride. A part of each liver obtained from FLS-ob/ob mice was homogenized in distilled water, and the total lipid was extracted. Triglyceride was measured by the glycerol-3-phosphate oxidase (GPO) $\mathrm{N}$-ethyl-N-(2-hydroxy3-sulfopropyl)-3,5-dimethoxyaniline (DAOS) method using Triglyceride E-test Wako (Wako Pure Chemical Industries, Ltd., Osaka, Japan).

Measurement of hepatic hydroxyproline (Hyp) content. Hepatic tissue (400 mg wet weight) was hydrolyzed in $4 \mathrm{ml}$ of $6 \mathrm{~N} \mathrm{HCl}$ at $105^{\circ} \mathrm{C}$ overnight. The hydrolysate was evapo- rated under vacuum 4 times. The sediment was redissolved in distilled water, mixed with activated charcoal for decolorization, and filtered. The solution was kept in the acidic range by adjustment to $\mathrm{pH} 5.0$ and evaporated under vacuum, and the sediment was redissolved in distilled water, supplemented with $2 \mathrm{ml}$ of isopropanol, and incubated with $1 \mathrm{ml}$ of $7 \%$ chloramine-T solution for $5 \mathrm{~min}$ at room temperature. Two milliliters of Ehrlich's solution, consisting of $1.76 \mathrm{~g}$ of p-dimethylaminobenzaldehyde dissolved in $4.08 \mathrm{ml}$ of $60 \%$ perchloric acid and $95.5 \mathrm{ml}$ of isopropanol, was added, and the mixture was incubated at $60^{\circ} \mathrm{C}$ for $10 \mathrm{~min}$. After cooling, absorbance was measured at $562 \mathrm{~nm}(17)$.

Measurement of hepatic fibrosis area with Sirius red staining. Sections $(4 \mu \mathrm{m})$ of formalin-fixed, paraffin-embedded liver were stained with picrosirius red and counter stained with fast green. The area of hepatic fibrosis was then measured in 10 randomly selected fields/section (magnification, $x 100$ ) per specimen using the Win ROOF version 5.71 software (Mitsutani Co., Tokyo, Japan).

Measurement of hepatic steatosis area. Sections $(4 \mu \mathrm{m})$ of formalin-fixed, paraffin-embedded liver were processed for staining with hematoxylin and eosin (H\&E). The area of hepatic steatosis was then measured using vascular fatty drops in $\mathrm{H} \& \mathrm{E}$ in 10 randomly selected fields/section (magnification, x100) per specimen using the Win ROOF version 5.71 software.

Immunostaining for $\alpha$-smooth muscle actin ( $\alpha$-SMA). Immunohistochemical staining of $\alpha$-SMA was performed using anti- $\alpha$-SMA antibody (Dako A/S, Glostrup, Denmark). To assess the activation grade of HSCs, the area of $\alpha$-SMA staining was measured using the Win ROOF version 5.71 software in 10 randomly selected fields/section (magnification, x100) per specimen.

RNA extraction and reverse transcription polymerase chain reaction (PCR) analysis. Tissue samples were homogenized and total-RNA was extracted using an RNeasy Lipid Tissue Mini kit (Qiagen, Hilden, Germany). The RNA concentration was determined by measuring the absorbance at $260 \mathrm{~nm}$, and the quality of RNA was verified by electrophoresis on ethidium-bromide-stained $1 \%$ agarose gels. Total-RNA $(\sim 2 \mu \mathrm{g})$ was then reverse transcribed (RT) in a final volume of $11.5 \mu 1$ containing $4 \mu \mathrm{l}$ of $5 \mathrm{X}$ standard buffer, $2 \mu 1$ of $0.1 \mathrm{M}$ dTT, $1 \mu 1$ of SuperScript II RNase $\mathrm{H}^{-}$reverse transcriptase (Invitrogen, Carlsbad, CA), $2 \mu 1$ of $10 \mathrm{M}$ dNTPs (Promega, Madison, WI), $1 \mu 1$ of $50 \mathrm{pmol} / \mu 1$ random primer (Promega), $0.5 \mu 1$ of $100 \mathrm{pmol} / \mu 1$ oligo(dt) 15 primer (Promega) and $1 \mu 1$ of $40 \mathrm{U} / \mu 1$ ribonuclease inhibitor (Wako Pure Chemical Industries). Samples were then incubated at $37^{\circ} \mathrm{C}$ for $60 \mathrm{~min}$ and $95^{\circ} \mathrm{C}$ for $5 \mathrm{~min}$, then cooled to $4^{\circ} \mathrm{C}$ for $5 \mathrm{~min}$.

Real-time PCR. Quantitative real-time PCR was performed in a final volume of $10 \mu 1$ containing $250 \mathrm{nM}$ Universal Probe Library probe (Roche Diagnostics, Basel, Switzerland), $900 \mathrm{nM}$ forward primer, $900 \mathrm{nM}$ reverse primer, $5 \mu 1$ EXPRESS qPCR Supermix with Premixed ROX (Invitrogen) and $2 \mu \mathrm{l}$ cDNA by real-time PCR assay (7900HT Fast Realtime PCR system; Applied Biosystems, Carlsbad, CA). The 
Table I. Body weight, liver weight, liver-to-body weight ratio, visceral fat weight and biochemical parameters in two groups.

\begin{tabular}{lcc}
\hline & $\begin{array}{c}\text { Control } \\
\text { group (n=8) }\end{array}$ & $\begin{array}{c}\text { Irbesartan } \\
\text { group (n=8) }\end{array}$ \\
\hline Body weight (g) & $56.6 \pm 4.6$ & $55.4 \pm 3.5$ \\
Liver weight (g) & $7.5 \pm 2.4$ & $7.7 \pm 1.4$ \\
Liver/body weight ratio & $0.13 \pm 0.032$ & $0.14 \pm 0.020$ \\
Hepatic triglyceride (mg/dl) & $1310 \pm 287$ & $1051 \pm 409$ \\
Visceral fat weight (g) & $2.2 \pm 0.27$ & $2.3 \pm 0.20$ \\
Blood chemistry & & \\
AST (IU/l) & $313 \pm 297$ & $118 \pm 20$ \\
ALT (IU/l) & $236 \pm 111$ & $96 \pm 41^{\mathrm{a}}$ \\
Triglyceride (mg/dl) & $310 \pm 83$ & $227 \pm 89$ \\
Cholesterol (mg/dl) & $272 \pm 68$ & $223 \pm 86$ \\
\hline
\end{tabular}

${ }^{\text {a }}<0.05$ compared with the control group.

mRNA levels of transforming growth factor- $\beta 1$ (TGF- $\beta 1$ ) (GenBank: NM_011577), procollagen-type I (GenBank; U08020), tissue inhibitor of metalloproteinases-1 (TIMP-1) (GenBank; NM_011593), connective tissue growth factor (CTGF) (NM_010217), tumor necrosis factor- $\alpha$ (TNF- $\alpha$ ) (GenBank: NM_013693), sterol regulatory element-binding protein 1c (SREBP1c) (GenBank: NM_0111480), peroxisome proliferator activated receptor (PPAR)- $\alpha$ (GenBank: NM_007988.3) and fatty acid synthase (FAS) (GenBank: NM_011144) were assessed using 7900HT Fast Real-Time PCR System with SDS2.3 software (Applied Biosystems) and $\beta$-actin (NM_007393) as an internal standard. Thermal cycle conditions were as follows: hold at $95^{\circ} \mathrm{C}$ for $20 \mathrm{sec}$, then 45 cycles of $95^{\circ} \mathrm{C}$ for $1 \mathrm{sec}$ and $60^{\circ} \mathrm{C}$ for $20 \mathrm{sec}$.

Analysis of inflammatory cells infiltrating in liver tissue. Immunohistochemical staining of F4/80 was performed using an anti F4/80 monoclonal antibody (Abcam, Tokyo, Japan) according to the manufacturer's instructions. Analysis of immunopositive cells was carried out in 10 intralobular ocular fields (magnification, x400) per specimen.

Analysis of oxidative stress and lipid peroxidation. Oxidative stress was evaluated by immunohistochemical staining and the content of 8-hydroxy-2-deoxyguanosine (8-OHdG), a marker of oxidative DNA damage (18). Immunohistochemical staining of 8-OHdG was performed using an anti 8-OHdG monoclonal antibody (Nikken Seil Co., Ltd., Shizuoka, Japan) according to the manufacturer's instructions. Analysis of immunopositive cells was carried out in 10 intralobular ocular fields (magnification, $\mathrm{x} 400$ ) per specimen, and was expressed as a percentage of fields using the Win ROOF version 5.71 software.

In the enzyme-linked immunosorbent assay (ELISA) of 8-OHdG, frozen liver tissues were homogenized and DNA was extracted using the Nal method and a DNeasy mini kit (Qiagen, Tokyo, Japan). After the DNA pellet was dissolved in
Table II. Levels of mRNA for procollagen I, TGF- $\beta 1$, TIMP-1, CTGF, TNF- $\alpha$, SREBP1c, PPAR- $\alpha$ and FAS in the two groups.

\begin{tabular}{lcc}
\hline & $\begin{array}{c}\text { Control } \\
\text { group }(\mathrm{n}=8)\end{array}$ & $\begin{array}{c}\text { Irbesartan } \\
\text { group }(\mathrm{n}=8)\end{array}$ \\
\hline Procollagen I $\left(\times 10^{-1}\right)$ & $2.01 \pm 1.91$ & $0.49 \pm 0.51^{\mathrm{a}}$ \\
TGF- $\beta 1\left(\times 10^{-2}\right)$ & $1.6 \pm 0.9$ & $0.8 \pm 0.4^{\mathrm{a}}$ \\
TIMP-1 $\left(\times 10^{-3}\right)$ & $7.1 \pm 10.4$ & $9.1 \pm 12.6$ \\
CTGF $\left(\times 10^{-2}\right)$ & $5.4 \pm 3.4$ & $4.5 \pm 2.0$ \\
TNF- $\alpha$ & $4.54 \pm 1.60$ & $2.34 \pm 0.71^{\mathrm{b}}$ \\
SREBP1c $(\mathrm{x} 10)$ & $1.83 \pm 0.44$ & $1.05 \pm 0.46^{\mathrm{b}}$ \\
PPAR- $\alpha$ & $2.31 \pm 0.58$ & $3.67 \pm 0.71^{\mathrm{b}}$ \\
FAS $(x 10)$ & $2.63 \pm 0.54$ & $0.98 \pm 0.33^{\mathrm{b}}$ \\
\hline
\end{tabular}

TGF- $\beta 1$, transforming growth factor- $\beta 1$; TIMP-1, tissue inhibitor of metalloproteinases-1; CTGF, connective tissue growth factor; TNF- $\alpha$, tumor necrosis factor- $\alpha$; SREBP1c, sterol regulatory element-binding protein 1c; PPAR- $\alpha$, peroxisome proliferator activated receptor- $\alpha$; FAS, fatty acid synthase. ${ }^{\mathrm{P}} \mathrm{P}<0.05,{ }^{\mathrm{b}} \mathrm{P}<0.01$ compared with the control group.

Tris/ethylenediaminetetraacetic acid (EDTA) buffer, $50 \mu \mathrm{g}$ of DNA was digested with nuclease P1 (Sigma-Aldrich, Tokyo, Japan) and alkaline phosphatase (Sigma-Aldrich), and centrifuged at 14,000 x g for $10 \mathrm{~min}$ through a Microcone YM-10 filter (Millipore, Bedford, MA). The level of $8-\mathrm{OHdG}$ in the extracted DNA solution was then determined using the highly sensitive 8-OHdG check ELISA kit (Nikken Seil Co., Ltd.). The absorbance of each well was measured at $450 \mathrm{~nm}$ using a microplate reader (U-2900; Hitachi). Immunohistochemical staining of 4-hydroxynoneal (4-HNE) was performed using anti-4-HNE monoclonal antibody (Nikken Seil Co., Ltd.) according to the manufacturer's instructions. We semi-quantitatively evaluated the 4-HNE immunostaining. Ten fields per specimen of 4-HNE staining were chosen randomly (magnification, $\mathrm{x} 200)$. We classified ten fields per specimen into 4 grades $(1,0-10 \% ; 2,10-20 \% ; 3,20-30 \% ; 4,>30 \%)$ according to the immunopositive area and calculated a mean value of ten fields.

Statistical analysis. The Mann-Whitney test was used to assess statistical significance of differences between groups. All statistical tests were carried out using StatView for Windows software (SAS Institute, Cary, NC, USA). All values are expressed as mean \pm standard deviation. Values of $\mathrm{P}<0.05$ were considered significant.

\section{Results}

Characteristics of mice in the two groups. To equalize the dietary intake among the two groups, we monitored food consumption and body weights throughout the observation period. No significant differences between groups were observed in terms of food consumption, body weight, liver weight, liver-to-body weight ratio or visceral fat weight (Table I).

Effects of irbesartan on blood chemistry. Blood triglyceride and total cholesterol were lower in the irbesartan group than control group, but this difference was not significant (Table I). 


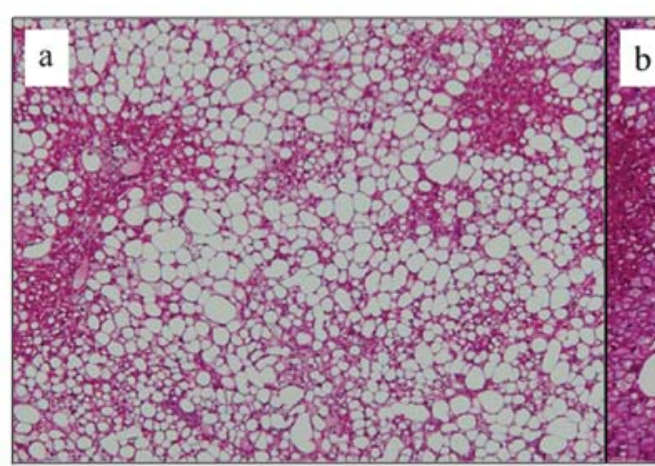

Control

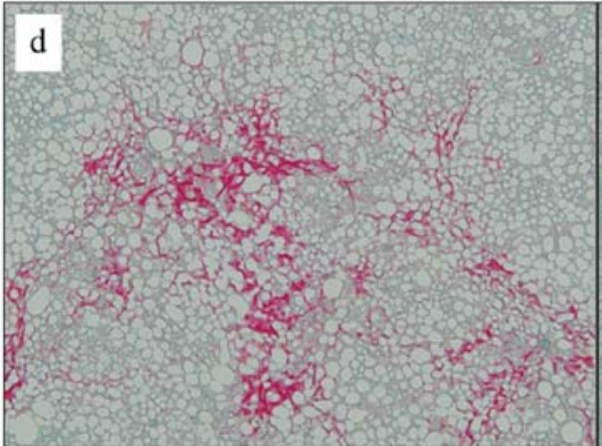

Control

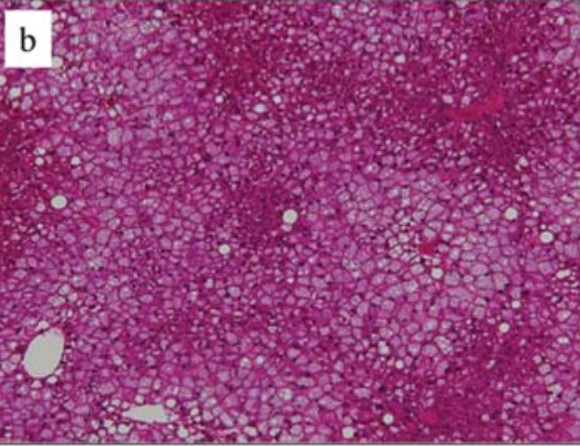

Irbesartan

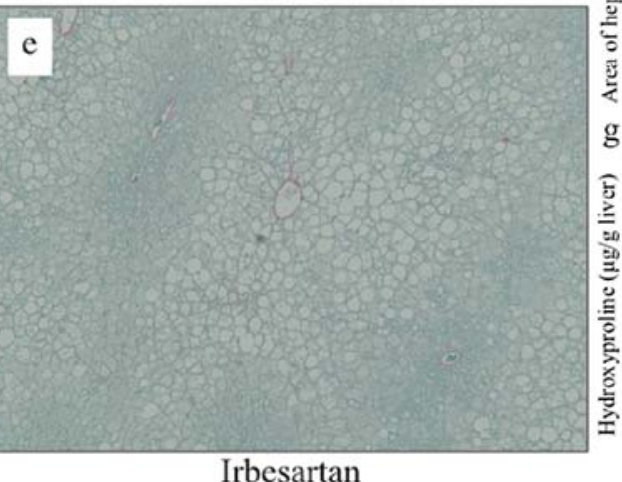

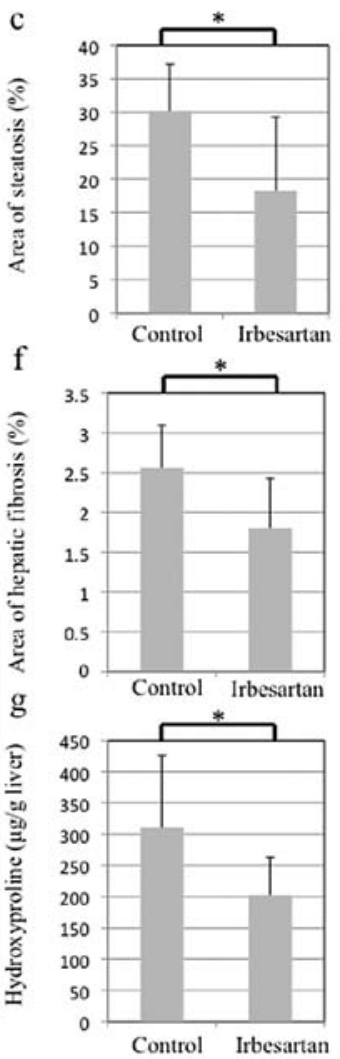

Figure 1. (a-c) Area of steatosis using H\&E staining (original magnification, x100). (a) Control group; (b) irbesartan group; (c) percentage area of hepatic steatosis in $\mathrm{H} \& \mathrm{E}$ staining measured using an image analysis system. ${ }^{*} \mathrm{P}<0.05$. (d-f) Area of Sirius red immunostaining (original magnification, $\mathrm{x} 100$ ). (d) Control group; (e) irbesartan group; (f) area of Sirius red immunostaining as measured using an image analysis system. (g) Comparison of hepatic hydroxyproline content between the groups. "P<0.05.
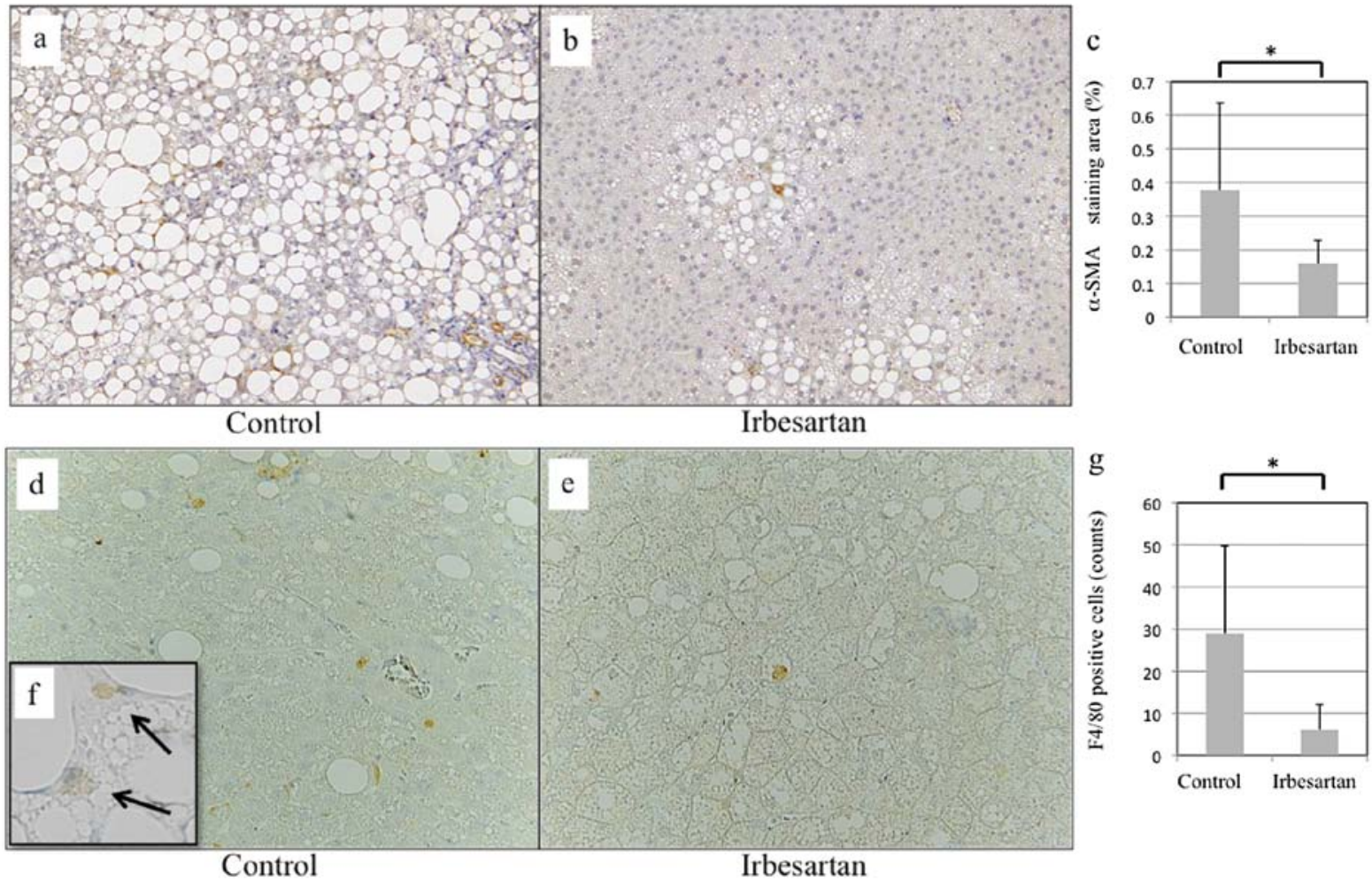

Figure 2. (a-e) Area of positive $\alpha$-SMA immunostaining (original magnification, x200). (a) Control group; (b) irbesartan group; (c) area of $\alpha$-SMA immunostaining as measured using an image analysis system. ${ }^{*} \mathrm{P}<0.05$. (d-g) F4/80 immunostaining for Kupffer cells (original magnification, $\mathrm{x} 200$ ). (d) Control group; (e) irbesartan group; (f) the high magnification image (original magnification, x1000) revealed Kupffer cells staining with F4/80 (arrows). (g) Comparison of the number of cells with positive F4/80 immunostaining between the two groups. ${ }^{*} \mathrm{P}<0.05$. 

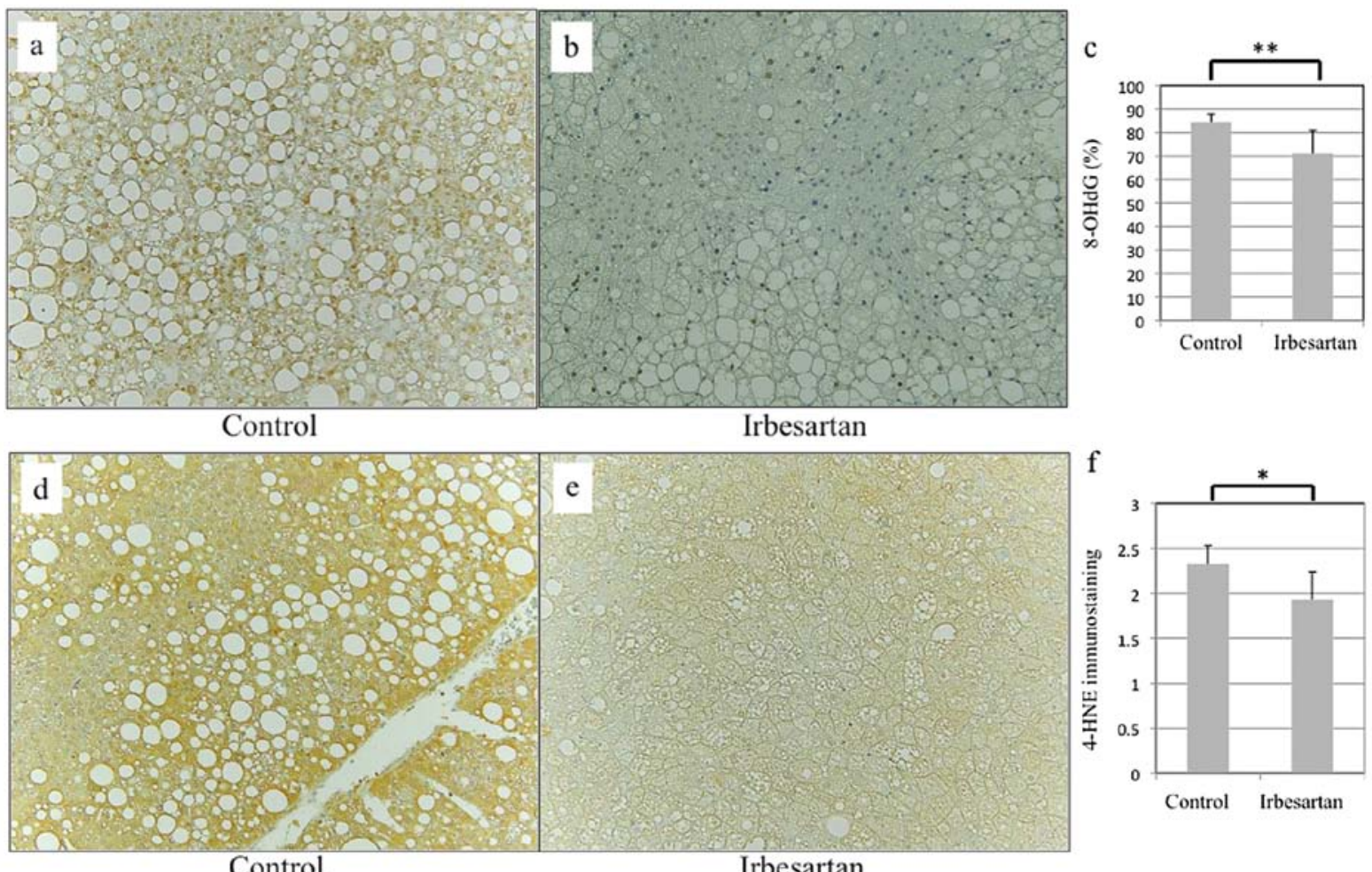

Control

Irbesartan

Figure 3. (a-c) Oxidative stress by 8-OHdG immunostaining (original magnification, x200) and hepatic 8-OHdG content. (a) Control group; (b) irbesartan group; (c) comparison of the number of 8-OHdG-positive cells between the two groups. ${ }^{* *} \mathrm{P}<0.01$. (d-f) Oxidative stress for 4-HNE immunostaining (original magnification, x200). (d) Control group; (e) irbesartan group; (f) comparison of the score obtained from the classification into 4 grades based on the 4-HNEpositive cytoplasmic staining in the two groups. ${ }^{*} \mathrm{P}<0.05$.

Plasma alanine transaminase (ALT) in the irbesartan group was significantly lower than in the control group.

Effects of irbesartan on hepatic steatosis. Hepatic triglyceride content was decreased to $1,051 \pm 409 \mathrm{mg} / \mathrm{dl}$ in the irbesartan group compared with control group $(1,310 \pm 287)$. H\&E staining showed that irbesartan reduced the area of hepatic steatosis, with $30.1 \pm 7.1 \%$ for controls, and $18.3 \pm 11.0 \%$ for the irbesartan group $(\mathrm{P}<0.05)$ (Fig. 1a-c). The mRNA levels of TNF- $\alpha$, SREBP1c and FAS in the irbesartan group were significantly decreased by 48,43 and $73 \%$, respectively and those of PPAR- $\alpha$ were significantly increased by $59 \%$ compared with those in controls (Table II).

Effects of irbesartan on hepatic fibrosis. Sirius red staining showed that the area of fibrosis was decreased with irbesartan administration, with $2.56 \pm 0.54 \%$ for controls, and $1.80 \pm 0.63 \%$ for the irbesartan group $(\mathrm{P}<0.05)$ (Fig. 1d-f). Hepatic Hyp content was also significantly lower in the irbesartan group $(203 \pm 60 \mu \mathrm{g} / \mathrm{g}$ wet liver) than in controls $(311 \pm 115 \mu \mathrm{g} / \mathrm{g}$ wet liver; $\mathrm{P}<0.05$ ) (Fig. 1g).

The data in Fig. 2a-c shows that irbesartan administration significantly reduced the area of positive $\alpha$-SMA immunostaining, with $0.38 \pm 0.26 \%$ for controls, and $0.16 \pm 0.07 \%$ for the irbesartan group $(\mathrm{P}<0.05)$.

Table II shows the expression of fibrogenic parameters in the liver. Irbesartan significantly reduced mRNA levels of procollagen I by $76 \%$. TGF- $\beta 1$ was significantly lower (by $50 \%$ ) in the irbesartan group than in controls. The mRNA levels of
TIMP-1 and CTGF tended to be lower in the irbesartan group than in controls, but no significant differences were identified.

Effects of irbesartan on inflammatory reactions in liver. Irbesartan markedly reduced the number of F4/80-positive cells, which represent liver macrophage Kupffer cells (Fig. 2d-g). The number of F4/80-positive cells in the irbesartan group was significantly decreased by $79 \%$ compared with those in the control group, with $28.96 \pm 20.78$ for controls, and $6.10 \pm 5.98$ for the irbesartan group $(\mathrm{P}<0.01)$. The mRNA of TNF- $\alpha$, proinflammatory cytokine, in the irbesartan group was significantly lower than that in the control group.

Effects of irbesartan on oxidative stress and lipid peroxidation. Irbesartan markedly reduced the percentage of $8-\mathrm{OHdG}$ positive cells in liver samples (Fig. 3a-c). Cells showing positive staining for $8-\mathrm{OHdG}$ were significantly decreased in the irbesartan group $(71.0 \pm 9.8 \%)$ compared to controls $(84.3 \pm 3.4 \%)(\mathrm{P}<0.01)$. Total $8-\mathrm{OHdG}$ DNA content was also significantly decreased following irbesartan administration, with $0.58 \pm 0.47 \mathrm{pg} / \mu \mathrm{g}$ for controls, and $0.49 \pm 0.97 \mathrm{pg} / \mu \mathrm{g}$ for the irbesartan group $(\mathrm{P}<0.05)$. Similarly, immunostaining grade for 4-HNE was significantly lower in the irbesartan group $(1.93 \pm 0.31)$ than in controls $(2.33 \pm 0.20 ; \mathrm{P}<0.05)$ (Fig. 3d-f).

\section{Discussion}

The present study identified favorable effects of irbesartan on liver steatosis and fibrosis. No differences in body weight, 
liver weight or visceral fat under the conditions of same food consumption were observed between controls and irbesartan groups. However, we demonstrated that the irbesartan significantly attenuated hepatic steatosis and reduced hepatic and plasma triglyceride levels, albeit not significant. Previous reports have shown that telmisartan and olmesartan also prevent steatosis in animal models of obesity in rats (19-21). AT-II infusion is known to stimulate hepatic triglyceride production in rats (22). In the present study, irbesartan reduced SREBP1c and FAS expression leading to the transcriptional activation of all lipogenic genes. The downregulation of SREBP1c and FAS expression by irbesartan may reduce hepatic lipogenesis. In fact, our previous study demonstrated that inhibition of SREBP1c by ezetimibe attenuated hepatic steatosis (23). Downregulation of SREBP1c is reportedly associated with the decreased levels of hepatic triglycerides in burned-out NASH (24).

Irbesartan upregulates hepatic expression of PPAR- $\alpha$ (25) and hepatic SREBP1c expression is directly regulated by PPAR- $\alpha$ (26). The present study also showed upregulated PPAR- $\alpha$ gene expression. Taken together, irbesartan reduced lipogenic gene expression via upregulated hepatic expression of PPAR- $\alpha$ and attenuated hepatic steatosis and hyperlipidemia. Furthermore, irbesartan has been reported to increase PPAR- $\gamma$ activity (27). The activation of a PPAR- $\alpha$ or $-\gamma$ agonist induces adipocyte differentiation and a reduction in the size of adipocytes (28). ARBs with partial agonistic activity of PPAR- $\gamma$ could improve adipocyte dysfunction, consequently reducing TNF- $\alpha$ and free fatty acids. The present study showed that irbesartan reduced the gene expression of TNF- $\alpha$. Taken together, hepatic steatosis reduced by irbesartan may also be due to effects exerted via PPAR- $\gamma$.

We found that irbesartan attenuated the progression of liver fibrosis, achieving the reductions in hepatic Hyp content, procollagen I mRNA and TGF- $\beta 1$ mRNA. Some studies have shown that ARB attenuates hepatic fibrosis in choline-deficient diet (CDD)- or methionine and CDD (MCDD)-induced steatohepatitis models (29-31). However, CDD- and MCDD-induced steatohepatitis are very different from human NASH in light of the metabolic syndrome. Few studies have demonstrated that ARB inhibits hepatic fibrosis in metabolic syndrome-related steatohepatitis (12). The present study clearly demonstrated that irbesartan inhibited hepatic fibrosis in FLS-ob/ob mice, representing similar conditions to human NASH with obesity. In many experimental models of liver injury, the RAS plays a major role in hepatic fibrosis (7-10). Our previous studies have already shown that suppression of the RAS inhibits hepatic fibrosis in the bile duct ligation (BDL)-rat model. AT-II promotes the proliferation and activation of hepatic stellate cells (HSCs), inflammation and oxidative stress (32). AT-II-induced expression of TGF- $\beta 1(33,34)$ and the overproduction of TGF- $\beta 1$ stimulates the synthesis of matrix proteins and inhibit matrix degradation through the activation of HSCs. The present findings reinforce the concept that AT-II also plays a major role in a model with steatohepatitis associated with obesity and insulin resistance.

To clarify the mechanisms underlying the antifibrotic effects, we examined the numbers of activated HSCs and the expression of profibrogenic cytokines such as TGF- $\beta 1, \mathrm{CTGF}$ and TIMP-1. We found that irbesartan reduced the numbers of activated HSCs and TGF- $\beta 1$ mRNA levels, but not CTGF or TIMP-1 mRNA levels. Other ARBs such as olmesartan and losartan have shown similar effects in MCDD-induced steatohepatitis models $(12,27,28)$.

We next carried out immunochemical analysis of 8-OHdG and 4-HNE to clarify the effects of irbesartan on oxidative stress. Oxidative stress plays a vital role as a second hit in the progression from steatosis to steatohepatitis. The oxidation of fatty acids represents an important source of reactive oxygen species (ROS). ROS induce lipid peroxidation and initiate DNA damage, which can be assessed as the formation of $8-\mathrm{OHdG}$. The present study found that irbesartan ameliorated $8-\mathrm{OHdG}$ immunostaining and 8-OHdG DNA content in the liver tissue. Furthermore, we observed that 4-HNE staining was lower in liver tissue from the irbesartan group than from controls. These results indicate that AT-II was involved as a source of ROS and that irbesartan attenuated the production of ROS.

Many studies have identified the importance of inflammation as another factor acting to provide the second hit. In the present study, irbesartan reduced the number of Kupffer cells infiltrating the liver and decreased TNF- $\alpha$ gene expression. Telmisartan has been reported to suppress the recruitment of macrophages to the liver and suppress the increase in TNF- $\alpha$ expression caused by MCDD (12). TNF- $\alpha$ is released by hepatocytes or Kupffer cells and activates HSCs in a paracrine manner (11). Reductions in TNF- $\alpha$ gene expression and Kupffer cells thus regulate not only inflammation, but also hepatic fibrosis.

The dose of irbesartan in the present study was $30 \mathrm{mg} / \mathrm{kg}$ body weight/day, which is approximately 6 -fold higher than the maximum dose for humans. Therefore, further study is needed to clarify its effectiveness for human NASH at a regular dose or a maximum dose. A variety of factors contribute to the development of human NASH, for example diabetes mellitus, obesity, hyperlipidemia and hypertension. The treatment for human NASH should combine cares and treatments for these several factors. ARBs may be the most effective option to use as part of a combination therapy.

In conclusion, irbesartan treatment improved hepatic steatosis by reducing the expression of SREBP1c and also attenuated the progression of hepatic fibrosis by inhibiting the activation of HSCs and decreasing oxidative stress and levels of inflammatory cytokines.

\section{References}

1. Pascale A, Pais R and Ratziu V: An overview of nonalcoholic steatohepatitis: past, present and future directions. J Gastrointestin Liver Dis 19: 415-423, 2010.

2. Hashimoto $\mathrm{E}$ and Tokushige K: Prevalence, gender, ethnic variations, and prognosis of NASH. J Gastroenterol 46 (Suppl 1): S63-S69, 2011.

3. Rector RS, Thyfault JP, Wei Y and Ibdah JA: Non-alcoholic fatty liver disease and the metabolic syndrome: an update. World $\mathbf{J}$ Gastroenterol 14: 185-192, 2008.

4. Manrique C, Lastra G, Gardner M and Sowers JR: The rennin angiotensin aldosterone system in hypertension: roles of insulin resistance and oxidative stress. Med Clin North Am 93: 569-582, 2009.

5. De Kloet AD, Krause EG and Woods SC: The renin angiotensin system and the metabolic syndrome. Physiol Behav 100: 525-534, 2010.

6. Ran J, Hirano T, Fukui T, Saito K, Kageyama H, Okada K and Adachi M: Angiotensin II infusion decreases plasma adiponectin level via its type 1 receptor in rats: an implication for hypertensionrelated insulin resistance. Metabolism 55: 478-488, 2006. 
7. Paizis G, Cooper ME, Schembri JM, Tikellis C, Burrell LM and Angus PW: Up-regulation of components of the renin-angiotensin system in the bile duct-ligated rat liver. Gastroenterology 123: 1667-1676, 2002.

8. Ueki M, Koda M, Yamamoto S, Matsunaga Y and Murawaki Y: Preventive and therapeutic effects of angiotensin II type 1 receptor blocker on hepatic fibrosis induced by bile duct ligation in rats. J Gastroenterol 41: 996-1004, 2006.

9. El-Demerdash E, Salam OMA, El-Batran SA, Abdallah HM and Shaffie NM: Inhibition of the renin-angiotensin system attenuates the development of liver fibrosis and oxidative stress in rats. Clin Exp Pharmacol Physiol 35: 159-167, 2008.

10. Ueki M, Koda M, Matono T, Sugihara T, Maeda K and Murawaki Y: Preventative and therapeutic effects of perindopril on hepatic fibrosis induced by bile duct ligation in rats. Mol Med Rep 2: 857-864, 2009

11. Ran J, Hirano T and Adachi M: Angiotensin II type 1 receptor blocker ameliorates overproduction and accumulation of triglyceride in the liver of Zucker fatty rats. Am J Physiol Endocrinol Metab 287: E227-E232, 2004

12. Toblli JE, Muñoz MC, Cao G, Mella J, Pereyra L and Mastai R: ACE inhibition and AT1 receptor blockade prevent fatty liver and fibrosis in obese Zucker rats. Obesity 16: 770-776, 2008.

13. Hirose A, Ono M, Saibara T, et al: Angiotension II type 1 receptor blocker inhibits fibrosis in rat nonalcoholic steatohepatitis. Hepatology 45: 1375-1381, 2007.

14. Larter CZ and Yeh MM: Animal models of NASH: getting both pathology and metabolic context right. J Gastroenterol Hepatol 23: 1635-1648, 2008.

15. Soga M, Kishimoto Y, Kawaguchi J, et al: The FLS mouse: a new inbred strain with spontaneous fatty liver. Lab Anim Sci 49: 269-275, 1999

16. Soga M, Hashimoto S, Kishimoto Y, Hirasawa T, Makino S and Inagaki S: Insulin resistance, steatohepatitis, and hepatocellular carcinoma in a new congenic strain of fatty liver Shionogi (FLS) mice with the Lep(ob) gene. Exp Anim 59: 407-419, 2010.

17. Murawaki Y and Hirayama C: Hepatic collagenolytic cathepsin in patients with chronic liver disease. Clin Chim Acta 108: 121-128, 1980.

18. Wu LL, Chiou CC, Chang PY and Wu JT: Urinary 8-OHdG: a marker of oxidative stress to DNA and a risk factor for cancer, atherosclerosis and diabetics. Clin Chem Acta 339: 1-9, 2004.

19. Araki K, Masaki T, Katsuragi I, Tanaka K, Kakuma T and Yoshimatsu H: Telmisartan prevents obesity and increases the expression of uncoupling protein 1 in diet-induced obese mice. Hypertension 48: 51-57, 2006.

20. Sugimoto K, Qi NR, Kazdová L, Pravence M, Ogihara T and Kurtz TW: Telmisartan but not valsartan increases caloric expenditure and protects against weight gain and hepatic steatosis Hypertension 47: 1003-1009, 2006.

21. Sturzeneker MCS, Ioshii SO, Baroncini LAV and Précoma DB: Olmesartan severely weakened the development of NASH in an animal model of hypercholesterolemia. Atherosclerosis 216 : 97-102, 2011.
22. Ran J, Hirano T and Adachi M: Chronic ANG II infusion increases plasma triglyceride level by stimulating hepatic triglyceride production in rats. Am J Physiol Endocrinol Metab 287: E955-E961, 2004.

23. Matono T, Koda M, Tokunaga S, Kato J, Sugihara T, Ueki M and Murawaki Y: The therapeutic effects of ezetimibe for nonalcoholic steatohepatitis in FLS-ob/ob mice. Hepatol Res 41: 1240-1248, 2011.

24. Nagaya T, Tanaka N, Suzuki T, et al: Down-regulation of SREBP-1c is associated with the development of burned-out NASH. J Hepatol 53: 724-731, 2010.

25. Rong X, Li Y, Ebihara K, et al: Irbesartan treatment upregulates hepatic expression of PPAR $\alpha$ and its target genes in obese Koletsky $\left(\mathrm{fa}^{\mathrm{k}} / \mathrm{fa}^{\mathrm{k}}\right)$ rats: a link to amelioration of hypertriglyceridaemia. Br J Pharmacol 160: 1796-1807, 2010.

26. Fernández-Alvarez A, Alvarez MS, Gonzalez R, Cucarella C, Muntané $\mathbf{J}$ and Casado M: Human SREBP1c expression in liver is directly regulated by peroxisome proliferator-activated receptor $\alpha$ (PPAR $\alpha$ ). J Biol Chem 286: 21466-21477, 2011.

27. Iwai M, Kanno H, Senba I, Nakaoka H, Moritani $T$ and Horiuchi M: Irbesartan increased PPAR $\gamma$ activity in vivo in white adipose tissue of atherosclerotic mice and improved adipose tissue dysfunction. Biochem Biophys Res Commun 406: 123-126, 2011.

28. Sharma AM and Staels R: Review:peroxisome proliferator-activated receptor $\gamma$ and adipose tissue - understanding obesity-related changes in regulation of lipid and glucose metabolism. J Clin Endocrinol Metab 92: 386-395, 2007.

29. Yoshiji H, Kuriyama S, Yoshii J, et al: Angiotensin-II type 1 receptor interaction is a major regulator for liver fibrosis development in rats. Hepatology 34: 745-750, 2001.

30. Yoshiji H, Noguchi R, Ikenaka Y, et al: Losartan, an angiotensin-II type 1 receptor blocker, attenuates the liver fibrosis development of non-alcoholic steatohepatitis in the rat. BMC Res Notes 2: 70, 2009.

31. Fujita K, Yoneda M, Wada K, et al: Telmisartan, an angiotensin II type 1 receptor blocker, controls progress of nonalcoholic steatohepatitis in rats. Dig Dis Sci 52: 3455-3464, 2007.

32. Bataller R, Ginès P, Nicolás JM, et al: Angiotensin II induces contraction and proliferation of human hepatic stellate cells. Gastroenterology 118: 1149-1156, 2000.

33. Bataller R, Gäbele E, Parsons CJ, et al: Systemic infusion of angiotensin II exacerbates liver fibrosis in the bile duct-ligated rats. Hepatology 41: 1046-1055, 2005.

34. Kudo H, Yata Y, Takahara T, et al: Telmisartan attenuates progression of steatohepatitis in mice: role of hepatic macrophage infiltration and effects on adipose tissue. Liver Int 29: 988-996, 2009. 